\title{
Modeling of gas-solid flow in a CFB riser based on computational particle fluid dynamics
}

\author{
Zhang Yinghui, Lan Xingying* and Gao Jinsen
}

State Key Laboratory of Heavy Oil Processing, China University of Petroleum, Beijing 102249, China

(C) China University of Petroleum (Beijing) and Springer-Verlag Berlin Heidelberg 2012

\begin{abstract}
A three-dimensional model for gas-solid flow in a circulating fluidized bed (CFB) riser was developed based on computational particle fluid dynamics (CPFD). The model was used to simulate the gas-solid flow behavior inside a circulating fluidized bed riser operating at various superficial gas velocities and solids mass fluxes in two fluidization regimes, a dilute phase transport (DPT) regime and a fast fluidization (FF) regime. The simulation results were evaluated based on comparison with experimental data of solids velocity and holdup, obtained from non-invasive automated radioactive particle tracking and gamma-ray tomography techniques, respectively. The agreement of the predicted solids velocity and holdup with experimental data validated the CPFD model for the CFB riser. The model predicted the main features of the gas-solid flows in the two regimes; the uniform dilute phase in the DPT regime, and the coexistence of the dilute phase in the upper region and the dense phase in the lower region in the FF regime. The clustering and solids back mixing in the FF regime were stronger than those in the DPT regime.
\end{abstract}

Key words: Gas-solid flow, circulating fluidized bed, computational particle fluid dynamics, modeling, hydrodynamics

\section{Introduction}

Circulating fluidized beds (CFBs) have some advantages in affecting contact between gas and particles, excellent heat and mass transfer and flexibility in handing particles with different densities and sizes (Grace et al, 2003). Therefore, CFBs are widely used in the petroleum industry, and the major commercial applications include fluid catalytic cracking (FCC) and combustion of petroleum coke. The increasing applications of CFBs call for more efficient technical processes. As the behavior of gas-solid flow in the CFB risers is quite complicated, it is still difficult to get a thorough understanding of the complex hydrodynamics. The design of current CFBs relies mainly on experience and empiricism. The design, scale-up and performance prediction of CFBs are still challenging tasks.

Currently, the numerical simulation approach provides a new and efficient tool to study the gas-solid hydrodynamics of CFBs. In general, two different approaches are used for simulation of gas-solid flow, namely Eulerian-Eulerian and Eulerian-Lagrangian methods. In the Eulerian-Eulerian approach (also referred as the two-fluid approach), the gas and particles are both considered as continuous phases which are fully inter-penetrating. Both phases are described in terms of different sets of conservation equations with interaction terms

*Corresponding author. email: lanxy@cup.edu.cn

Received January 17, 2012 representing the coupling between phases. Nowadays, the Eulerian-Eulerian approach is the most applicable method for simulating the gas-solid flow in CFBs (Benyahia et al, 2000; Neri and Gidaspow, 2000; Zheng et al, 2001; Almuttahar and Taghipour, 2008; Lu et al, 2008; Jin et al, 2010). Though the physical characteristics of particles, such as the size and shear stress, are included in the empirical relationship, this approach cannot recognize the discrete characteristics of solids phase. The Eulerian-Eulerian approach has some difficulty in calculating the flow of particles of various sizes and types, as the continuity and momentum equations must be solved for each size and type (Gidaspow, 1994).

The Eulerian-Lagrangian approach (also referred as the discrete particle method, DPM) treats the particles individually and directly calculates the motion of each particle through the forces acting on it. This method allows the solution for flows with a wide range of particle types, sizes, shapes, and velocities ( $\mathrm{Wu}$ et al, 2010). This approach has also been used to calculate the gas-solid flow in fluidized beds (Zhu et al, 2008; Sakai et al, 2010; Kafui et al, 2011). Chiesa et al (2005) compared the results obtained from the discrete particle method and the two-fluid approach, and concluded that the results obtained from the EulerianLagrangian approach showed a much better agreement with the experimental results than that obtained by the EulerianEulerian approach. However, numerical simulation by the Eulerian-Lagrangian approach is very computationally complex. The DPM calculations have been limited to the 
order of $2 \times 10^{5}$ particles and are often restricted to twodimensional solutions (Godlieb et al, 2007). The DPM cannot be yet used for the simulation of large scale CFBs with more than $10^{12}$ particles.

Recently the computational particle fluid dynamic (CPFD) method proposed by Snider (2001) has been applied to model fluidized beds and achieves reasonable predictions of gassolid flow (O'Rourke et al, 2009; Abbasi et al, 2011; Snider et al, 2011). The CPFD method treats the gas as a continuous phase and models the particles as discrete particles. The method is a form of discrete element method (DEM), where each particle has three-dimensional forces from fluid drag, gravity, static dynamic friction, particle collision and other possible forces. In the CPFD method, particles are grouped into numerical-particles. Each numerical-particle is composed of a number of real particles with same properties, such as density, size, position and velocity. A numerical-particle is smaller than the grid cell, and thus each cell contains multiple numerical-particles. These numerical-particles move freely within the whole computational domain and are tracked in the Lagrangian approach. Using numerical-particles, large scale systems including billions of particles can be simulated using only millions of numerical-particles. Furthermore, unlike the DEM model which calculates the collision force between particles by a spring-damper model directly, the CPFD method models the collision force on each particle using a spatial gradient model. The effect of particle collisions is accounted in an average manner using a continuum model of particle phase stress (Snider, 2007).

In the present work, the new developed CPFD method was applied to simulate the gas-solid flow in a CFB riser. The approach was evaluated using experimental results obtained by computer automated radioactive particle tracking (CARPT) and gamma ray Computed Tomography (CT).

\section{Experimental setup}

The validation of simulation is generally implemented by comparing the simulated results with experimental data. Thus, the present simulation work is based on a 'cold flow' circulating fluidized bed facility (Fig. 1) installed at the Chemical Reaction Engineering Laboratory (CREL) at Washington University (Bhusarapu et al, 2006). The riser has an internal diameter of $0.152 \mathrm{~m}$ and a total height of 7.9 $\mathrm{m}$. Approximately spherical glass beads are fluidized with air. The density of particles is $2,550 \mathrm{~kg} \cdot \mathrm{m}^{-3}$, and the mean diameter is $150 \mu \mathrm{m}$. Non-invasive CARPT is conducted to measure the solids velocity distribution. All the CARPT results were in the fully developed section between the height of $Z=5.1 \mathrm{~m}$ and $5.6 \mathrm{~m}$. The gamma ray CT technique is used to quantify the solids holdup profiles at the zone between $Z=5.0 \mathrm{~m}$ and $5.47 \mathrm{~m}$. Further details of experimental techniques and results can be found in Bhusarapu et al (2004; 2005; 2007).

The CPFD approach is evaluated by comparing the predictions with the experimental results at three sets of operating conditions. We studied three cases with different superficial gas velocities $\left(U_{\mathrm{g}}\right)$ and solids mass fluxes $\left(G_{\mathrm{s}}\right)$. The three operating conditions are listed in Table 1. According to

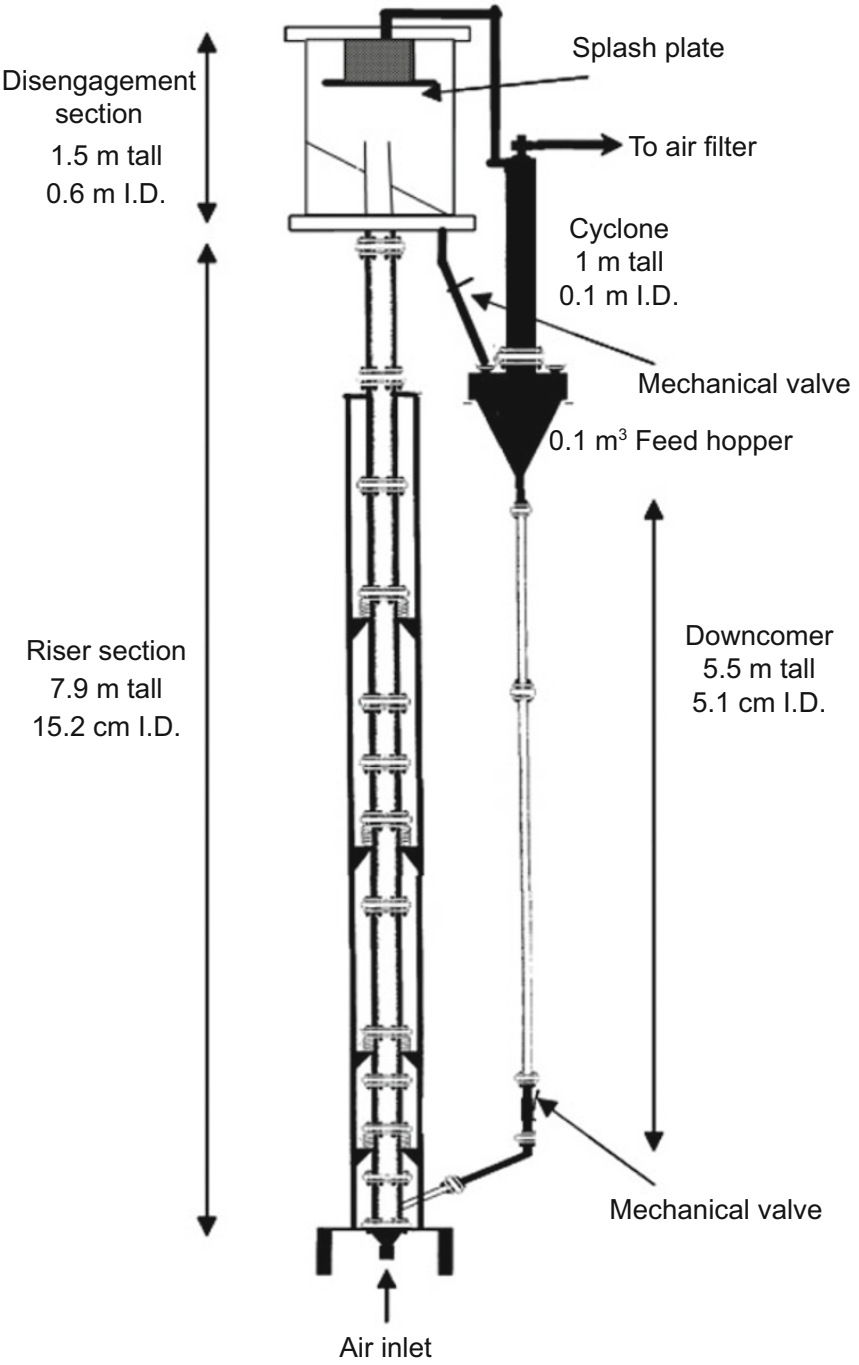

Fig. 1 Schematic diagram of the CREL riser

literature (Bhusarapu et al, 2006), cases 1 and 2 belong to the dilute phase transport (DPT) regime, and case 3 is in the fast fluidization (FF) regime. All of them are considered as the low-density CFBs (Zhu and Bi, 1995).

Table 1 Summary of operating conditions

\begin{tabular}{cccc}
\hline Operating condition & $\begin{array}{c}\text { DPT regime } \\
\text { Case 1 }\end{array}$ & $\begin{array}{c}\text { DPT regime } \\
\text { Case 2 }\end{array}$ & $\begin{array}{c}\text { FF regime } \\
\text { Case 3 }\end{array}$ \\
\hline$U_{\mathrm{g}}, \mathrm{m} \cdot \mathrm{s}^{-1}$ & 4.5 & 3.9 & 3.2 \\
$G_{\mathrm{s}}, \mathrm{kg} \cdot \mathrm{m}^{-2} \cdot \mathrm{s}^{-1}$ & 36.8 & 33.7 & 26.6 \\
\hline
\end{tabular}

\section{CPFD model}

\subsection{Governing equations}

In the computational particle fluid dynamic (CPFD) method, the gas phase is treated as fluid and calculated using Eulerian computational grids, while the particle phase is modeled as discrete particles using Lagrangian numerical-particles. The fluid phase is described by mass and momentum conservation equations with strong coupling to the particle phase, whereas the particle phase is represented by the particle probability distribution function. 
The continuity equation for gas phase is

$$
\frac{\partial \theta_{\mathrm{g}} \rho_{\mathrm{g}}}{\partial t}+\nabla \cdot\left(\theta_{\mathrm{g}} \rho_{\mathrm{g}} u_{\mathrm{g}}\right)=0
$$

where $u_{\mathrm{g}}$ is the gas velocity, $\rho_{\mathrm{g}}$ is the gas density and $\theta_{\mathrm{g}}$ is the gas volume fraction.

The momentum equation for gas phase is

$$
\begin{aligned}
& \frac{\partial\left(\theta_{\mathrm{g}} \rho_{\mathrm{g}} u_{\mathrm{g}}\right)}{\partial t}+\nabla \cdot\left(\theta_{\mathrm{g}} \rho_{\mathrm{g}} u_{\mathrm{g}} u_{\mathrm{g}}\right) \\
& =-\theta_{\mathrm{g}} \nabla P+\theta_{\mathrm{g}} \mu_{\mathrm{g}} \nabla^{2} u_{\mathrm{g}}+\theta_{\mathrm{g}} \rho_{\mathrm{g}} g-F
\end{aligned}
$$

where $P$ is the gas pressure, $\mu_{\mathrm{g}}$ is the gas viscosity, $g$ is the gravitational acceleration and $F$ is the rate of momentum exchange per volume between gas and particle phases. The gas phase is compressible, and the gas and particle phases are isothermal.

For the particle phase, the dynamics are described using the probability distribution function $f\left(x, u_{\mathrm{p}}, \rho_{\mathrm{p}}, V_{\mathrm{p}}, t\right)$, where $x$ is the particle position, $u_{\mathrm{p}}$ is the particle velocity, $\rho_{\mathrm{p}}$ is the particle density, $V_{\mathrm{p}}$ is the particle volume and $t$ is the time. The time evolution of $f$ is obtained by solving a Liouville equation, which is the mathematical statement of conservation of the particle numbers in volumes moving along dynamic trajectories in the particle phase space.

The Liouville equation for particle positions is

$$
\frac{\partial f}{\partial t}+\nabla\left(f u_{\mathrm{p}}\right)+\nabla_{u_{\mathrm{p}}}(f A)=0
$$

where $A$ is the particle acceleration and $\nabla_{u_{v}}$ is the divergence operator with respect to the velocity. By solving the Liouville equation the future coordinates of the particle positions can be obtained based on its present coordinates and the particle properties. It is assumed that the mass of each particle is constant through time (no mass transfer between particles or to the fluid), while the size and density of particles can have a distribution. The particle probability distribution function integrated over velocity, density and volume of all particles gives the probable number of particles per unit volume at position $x$ and time $t$ that have the velocity, density and volume in the interval of $\left(u_{\mathrm{p}}, u_{\mathrm{p}}+\mathrm{d} u_{\mathrm{p}}\right),\left(\rho_{\mathrm{p}}, \rho_{\mathrm{p}}+\mathrm{d} \rho_{\mathrm{p}}\right)$ and $\left(V_{\mathrm{p}}\right.$, $\left.V_{\mathrm{p}}+\mathrm{d} V_{\mathrm{p}}\right)$.

The particle acceleration equation is

$$
A=\frac{1}{\rho_{\mathrm{p}}} D\left(u_{\mathrm{g}}-u_{\mathrm{p}}\right)-\frac{1}{\rho_{\mathrm{p}}} \nabla p+g-\frac{1}{\theta_{\mathrm{p}} \rho_{\mathrm{p}}} \nabla \tau_{\mathrm{p}}
$$

where $D$ is the interphase drag force, $\theta_{\mathrm{p}}$ is the particle volume fraction and $\tau_{\mathrm{p}}$ is the particle normal stress.

The particle volume fraction in each cell is

$$
\theta_{\mathrm{p}}=\iiint f V_{\mathrm{p}} \mathrm{d} V_{\mathrm{p}} \mathrm{d} \rho_{\mathrm{p}} \mathrm{d} u_{\mathrm{p}}
$$

The momentum exchange between fluid and particle phases is

$$
F=\iiint f V_{\mathrm{p}} \rho_{\mathrm{p}}\left[D\left(u_{\mathrm{g}}-u_{\mathrm{p}}\right)-\frac{1}{\rho_{\mathrm{p}}} \nabla p\right] \mathrm{d} V_{\mathrm{p}} \mathrm{d} \rho_{\mathrm{p}} \mathrm{d} u_{\mathrm{p}}
$$

Generally, the main difference between the CPFD approach and the commonly used two-fluid model is the method to describe interphase momentum exchange. In the CPFD method, the interphase momentum transfer function is more detailed than in the two-fluid model. In the twofluid model, the momentum exchange rate is presented to be proportional to the difference of the average velocities of the two phases. However, in the CPFD method, the particle distribution function is first solved, and then the detailed interphase momentum exchange is obtained by summing up the contributions from particles with different velocities and sizes.

\subsection{Gas-particle drag model}

The drag model, representing the interaction between gas and particle phases, is a key factor in successful simulation. The drag model used here is the combination of the works of Ergun (1952) and Wen and Yu (1966). The Ergun correlation was developed for systems with particle volume fractions ranging from 0.47 to 0.7 , whereas Wen and Yu carried out the investigation for the systems with the solids volume fractions between 0.01 and 0.61 . Therefore, in the drag model of WenYu model combined with Ergun model, Wen-Yu correlation is used for solid volume fractions smaller than $0.75 \theta_{\mathrm{CP}}$, while Ergun equation is used for solid volume fractions greater than $0.85 \theta_{\mathrm{CP}}$, where $\theta_{\mathrm{CP}}$ represents the solid volume fraction at close packing. In order to prevent possible problems in numerical simulation due to the discontinuity and sharp transition in the drag model, a transition function is used for the solid volume fractions between $0.75 \theta_{\mathrm{CP}}$ and $0.85 \theta_{\mathrm{CP}}$. In this study, the particle-phase volume fraction at close packing is 0.64 , so the transition between the two correlations is in the range of solid volume fraction between 0.48 and 0.54 .

The drag model of Wen-Yu correlation combined with Ergun correlation is shown in Table 2. $D$ is the drag force, $D_{1}$ is the drag force in the Wen and Yu model, $D_{2}$ is the drag force in the Ergun model, $C_{\mathrm{d}}$ is the drag coefficient and $R e$ is the Reynolds number.

\subsection{Particle normal stress model}

The particle-particle collisions are modeled by a particle normal stress. The particle stress derives from the particle volume fraction, which is calculated from particle volume mapped to the grid. The particle normal stress model used in this study is an extension of the model by Harris and Crighton (1994).

The equation of the particle normal stress model is

$$
\tau_{\mathrm{p}}=\frac{P_{\mathrm{s}} \theta_{\mathrm{p}}^{\beta}}{\max \left[\left(\theta_{\mathrm{cp}}-\theta_{\mathrm{p}}\right), \varepsilon\left(1-\theta_{\mathrm{p}}\right)\right]}
$$

where $P_{\mathrm{s}}$ is a constant with units of pressure, $\beta$ is a constant recommended between 2 and 5 , and $\varepsilon$ is a small number on the order of $10^{-7}$.

\subsection{Solution procedure}

The particle properties are mapped to and from the Eulerian grid using the interpolation operators. The three- 
dimensional interpolation operator is the product of directional operators in the three orthogonal directions $(x$, $y, z)$. For one particle located at $x_{\mathrm{p}}(x, y, z)$, the $x$-directional component of interpolation operator $\left(S_{i}^{x}\right)$ to grid cell $i$ is an even function, which has nothing to do with the $y$ and $z$ coordinates.

Table 2 Equations of drag model (Wen-Yu correlation combined with Ergun correlation)

$$
\begin{aligned}
& \begin{array}{l}
\text { Wen-Yu model } \\
R e
\end{array} \quad 0.5 \quad C_{\mathrm{d}}=\frac{24}{R e} \theta_{\mathrm{g}}^{-2.65} \\
& 0.5 \leq \operatorname{Re} \leq 1000 \quad C_{\mathrm{d}}=\frac{24}{R e}\left(1+0.15 R e^{0.687}\right) \theta_{\mathrm{g}}^{-2.65} \\
& R e>1000 \quad C_{\mathrm{d}}=0.44 \theta_{\mathrm{g}}^{-2.65} \\
& D_{1}=0.75 C_{\mathrm{d}} \frac{\rho_{\mathrm{g}}}{\rho_{\mathrm{p}}} \frac{\left|u_{\mathrm{g}}-u_{\mathrm{p}}\right|}{d} \\
& R e=\frac{\rho_{\mathrm{g}} d_{\mathrm{p}}\left|u_{\mathrm{g}}-u_{\mathrm{p}}\right|}{u_{\mathrm{g}}}
\end{aligned}
$$

Ergun model

$$
\begin{aligned}
& D_{2}=\left(\frac{180 \theta_{\mathrm{p}}}{\theta_{\mathrm{g}} R e}+2\right) \frac{\rho_{\mathrm{g}}}{\rho_{\mathrm{p}}} \frac{\left|u_{\mathrm{g}}-u_{\mathrm{p}}\right|}{d} \\
& \operatorname{Re}=\frac{\rho_{\mathrm{g}} d_{\mathrm{p}}\left|u_{\mathrm{g}}-u_{\mathrm{p}}\right|}{u_{\mathrm{g}}}
\end{aligned}
$$

Combination of the Wen-Yu and Ergun models

$$
\begin{array}{ll}
\theta_{\mathrm{p}}<0.75 \theta_{\mathrm{CP}} & D=D_{1} \\
0.75 \theta_{\mathrm{CP}} \leq \theta_{\mathrm{p}} \leq 0.85 \theta_{\mathrm{CP}} & D=\frac{\theta_{\mathrm{p}}-0.85 \theta_{\mathrm{CP}}}{0.85 \theta_{\mathrm{CP}}-0.75 \theta_{\mathrm{CP}}}\left(D_{2}-D_{1}\right)+D_{1} \\
\theta_{\mathrm{p}}>0.85 \theta_{\mathrm{CP}} & D=D_{2}
\end{array}
$$

$$
S_{\mathrm{i}}^{x}\left(x_{\mathrm{p}}\right)= \begin{cases}0 & x_{i-1} \geq x_{\mathrm{p}} \geq x_{i+1} \\ 1 & x_{\mathrm{p}}=x_{i}\end{cases}
$$

The interpolation operators in $y$ and $z$ directions have the similar form. By mapping the particle volumes to the grid, the particle volume fraction $\theta_{i, j, k}$ at grid cell $(i, j, k)$ is

$$
\theta_{i, j, k}=\frac{1}{V_{i, j, k}} \sum_{\kappa=1}^{N_{\mathrm{p}}} n_{\mathrm{p}} V_{\mathrm{p}} S_{i, j, k}
$$

where $V_{i, j, k}$ is the grid cell volume, $V_{\mathrm{p}}$ is particle volume, $N_{\mathrm{p}}$ is the total number of numerical-particles and each numericalparticle contains $n_{\mathrm{p}}$ real particles, $S_{i, j, k}$ is the interpolation operator. The new gas volume fraction can be updated by the total solids volume fraction. The gas volume fraction will be used for solving gas continuity and momentum equations in the next time step.

The particle velocity is updated from the numerical integration of the particle velocity equation.

$$
u_{\mathrm{p}}^{n+1}=\frac{u_{\mathrm{p}}^{n}+\Delta t\left[D u_{\mathrm{g}, \mathrm{p}}^{n+1}-\frac{1}{\rho_{\mathrm{p}}} \nabla p_{\mathrm{p}}^{n+1}-\frac{1}{\rho_{\mathrm{p}} \theta_{\mathrm{p}}} \nabla \tau_{\mathrm{p}}^{n+1}+g\right]}{1+\Delta t D}
$$

where $u_{\mathrm{p}}^{n+1}$ is the interpolated implicit particle velocity at the particle location, $u_{\mathrm{g}, \mathrm{p}}^{n+1}$ is the interpolated implicit fluid velocity at the particle location, $\nabla p_{\mathrm{p}}^{n+1}$ stands for the interpolated implicit pressure gradient at the particle location, $\nabla \tau_{\mathrm{p}}^{n+1}$ means the interpolated solid stress gradient at the particle location and $D$ represents the drag force. Following the particle velocity calculation, the particle positions are updated.

The following implicit equation is used to calculate the new-time particle positions.

$$
x_{\mathrm{p}}^{n+1}=x_{\mathrm{p}}^{n}+u_{\mathrm{p}}^{n+1} \Delta t
$$

\section{Results and discussion}

The cold circulating fluidized bed riser at the CREL was simulated by using the commercial CPFD software Barracuda under different conditions in two regimes; a fast fluidization regime and a dilute phase transport regime. The gas phase inlet is at the base of the riser, and the inlet velocity of the gas phase is determined from the superficial gas velocity. The inlet of the particle phase is a small side entrance near the bottom of the riser, and the particle mass flow rate is defined according to the solids mass flux. The top of the riser is set as the out flow condition at atmosphere pressure. The main parameters used in the simulation are listed in Table 3.

Table 3 Simulation parameters

\begin{tabular}{cc}
\hline Parameter & Value \\
\hline Particle diameter & $150 \mu \mathrm{m}$ \\
Particle density & $2550 \mathrm{~kg} \cdot \mathrm{m}^{-3}$ \\
Gas viscosity & $1.84 \times 10^{-5} \mathrm{~kg} \cdot \mathrm{m}^{-1} \cdot \mathrm{s}^{-1}$ \\
Particle-phase volume fraction at close & \\
packing & 0.64 \\
Tangent-to-wall momentum retention & 0.99 \\
Normal-to-wall momentum retention & 0.1 \\
Diffuse bounce & 2 \\
Turbulence model & Algebraic \\
Grid size & $1.17 \times 1.17 \times 2.63 \mathrm{~cm}$ \\
Time step & $0.001 \mathrm{~s}$ \\
Simulation time & $100-600 \mathrm{~s}$ \\
\hline
\end{tabular}

\subsection{Comparison between simulation results and experimental data}

A comparison between simulation results and experimental data was carried out between bed heights $(z)$ of $5.1 \mathrm{~m}$ and $5.6 \mathrm{~m}$. Fig. 2 and Fig. 3 display the simulation and experimental results of the time-averaged solids volume fraction and axial particle velocity, respectively. It can be seen that the simulations successfully reproduce the general trend of the experimental results. For the dilute phase transport (DPT) regime, the solids volume fractions in Fig. 2(a) and Fig. 2(b) show good agreement with experimental data close to the wall, but are over predicted in the center. For the fast 
(a) DPT regime

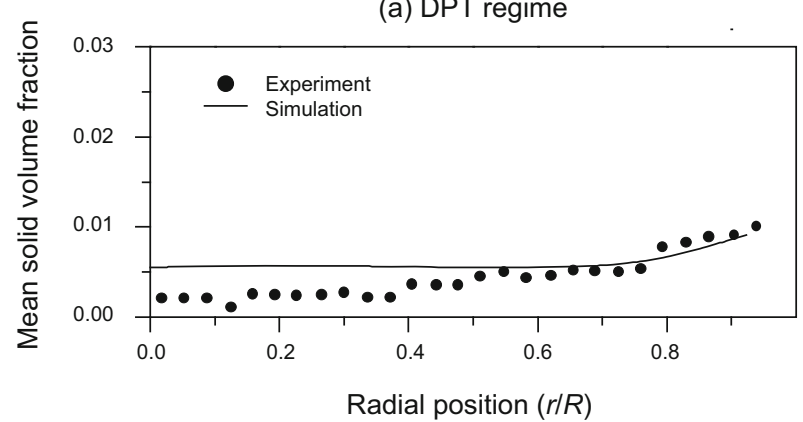

(b) DPT regime

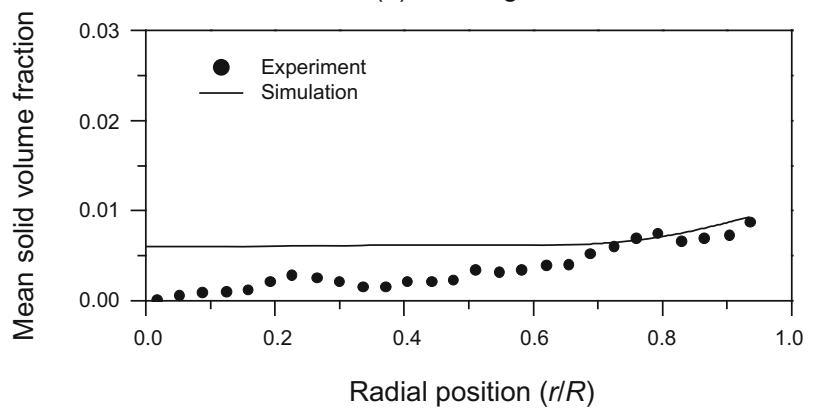

(c) FF regime

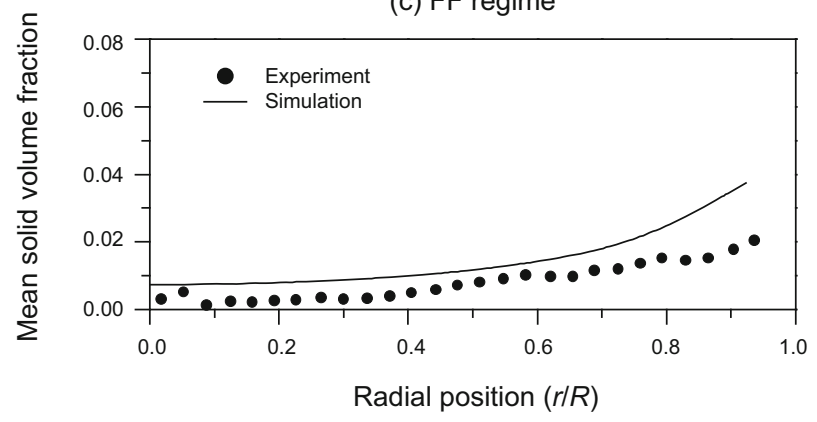

Fig. 2 Radial profiles of mean solid volume fraction, (a) $U_{\mathrm{g}}=4.5 \mathrm{~m} \cdot \mathrm{s}^{-1}$, $G_{\mathrm{s}}=36.8 \mathrm{~kg} \cdot \mathrm{m}^{-2} \cdot \mathrm{s}^{-1}$ (DPT regime); (b) $U_{\mathrm{g}}=3.9 \mathrm{~m} \cdot \mathrm{s}^{-1}, G_{\mathrm{s}}=33.7 \mathrm{~kg} \cdot \mathrm{m}^{-2} \cdot \mathrm{s}^{-1}$ (DPT regime); (c) $U_{\mathrm{g}}=3.2 \mathrm{~m} \cdot \mathrm{s}^{-1}, G_{\mathrm{s}}=26.6 \mathrm{~kg} \cdot \mathrm{m}^{-2} \cdot \mathrm{s}^{-1}$ (FF regime)

fluidization (FF) regime, the predicted solids volume fractions shown in Fig. 2(c) are a little higher than the experimental data both in the center and close to the wall. The simulation results and experimental data of axial particle velocities are shown in Fig. 3. The predicted particle velocities agree well with experimental data in the DPT regime, while the particle velocity in the center is over predicted in the FF regime.

The discrepancy may come from some simplifications made in the model. The particle size distribution (PSD) significantly affects the gas-solid flow in fluidized beds (Grace and Sun, 1991; Chew et al, 2010), thus it is important to take the PSD effects into account in the simulation. Using an average particle size may cause some errors. In addition, the effect of turbulence on the flow behavior might be important when modeling fast fluidized beds. Neri and Gidaspow (2000) and Almuttaharn and Taghipour (2008) predicted the flow characteristics in CFBs with an overall solids volume fraction less than $10 \%$ without adopting the turbulence model. In the investigation of Almuttaharn and Taghipoour (2008), the predicted solids holdup was considerably higher than the

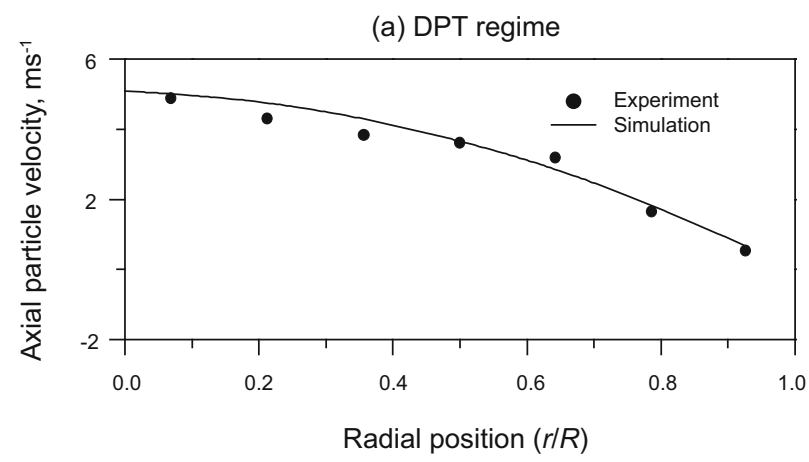

(b) DPT regime

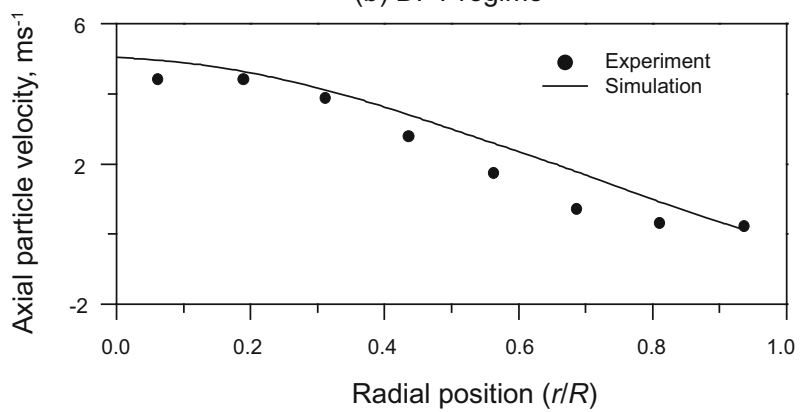

(c) FF regime

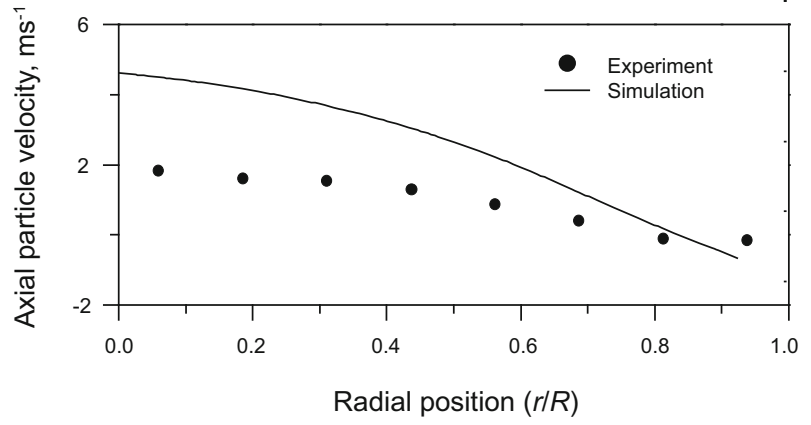

Fig. 3 Radial profiles of mean axial particle velocity, (a) $U_{\mathrm{g}}=4.5 \mathrm{~m} \cdot \mathrm{s}^{-1}$, $G_{\mathrm{s}}=36.8 \mathrm{~kg} \cdot \mathrm{m}^{-2} \cdot \mathrm{s}^{-1}$ (DPT regime); (b) $U_{\mathrm{g}}=3.9 \mathrm{~m} \cdot \mathrm{s}^{-1}, G_{\mathrm{s}}=33.7 \mathrm{~kg} \cdot \mathrm{m}^{-2} \cdot \mathrm{s}^{-1}$ (DPT regime); (c) $U_{\mathrm{g}}=3.2 \mathrm{~m} \cdot \mathrm{s}^{-1}, G_{\mathrm{s}}=26.6 \mathrm{~kg} \cdot \mathrm{m}^{-2} \cdot \mathrm{s}^{-1}$ (FF regime)

experimental data in the center, and in the work of Neri and Gidaspow (2000) most of the core solids holdup was higher than the experimental data. However, Chan et al (2005) obtained an acceptable agreement of modeling results with the turbulence model in a low density riser. In the work by Chan et al (2005), in order to calculate the turbulent kinetic energy and dissipation rate of the particle phase, a modified turbulence model $\left(k-\varepsilon-k_{\mathrm{p}}-\varepsilon_{\mathrm{p}}\right)$ was developed for calculating the gas-solid flow. Compared with the k- $\varepsilon$ turbulence model, the modified model gave a more reasonable particle axial velocity distribution in the core region and solids volume fraction distribution in the annulus region. Therefore, the predicted results of CFPD modeling can be further improved by taking the particle size distribution into consideration and adopting a suitable turbulence model.

\subsection{Solids volume fraction}

Fig. 4 and Fig. 5 illustrate the time-averaged solids concentration contours under three operating conditions in two flow regimes, and Fig. 6 shows the axial time-averaged 
solids volume fraction. In the DPT regime, the solid volume fraction is very low in the whole riser and it declines gradually with bed height, showing a little variation between the lower zone and the upper zone. For the FF regime, however, it can be seen in Fig. 4(c) that the solids volume fraction decreases sharply with bed height. A relative dense phase in the lower region of the riser and a dilute phase in the upper region coexist. The solids volume fraction in the lower region below the height of $3.2 \mathrm{~m}$ is higher than 0.1 , as shown in Fig. 6. The time-averaged solids concentration contours at a horizontal section of $Z=5.46 \mathrm{~m}$ is shown in Fig. 5. The distribution of solids concentration seems to be centrosymmetric, indicating that the solids flow pattern in the riser is axis-symmetric. For all the three conditions, the solids concentrations close to the wall are higher than that in the center. Therefore, the phenomenon of particle clustering is more likely to occur close to the wall than in the center. In the DPT regime, the solids volume fraction is relatively low and shows little variation. However, in the FF regime, the solids

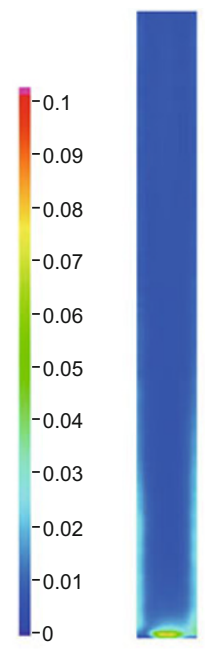

(a) DPT regime

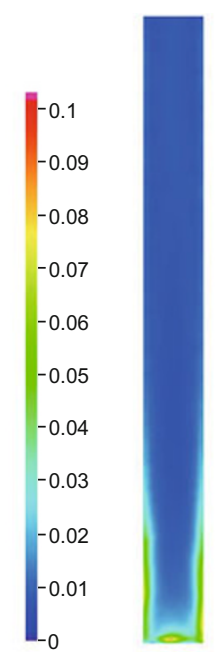

(b) DPT regime

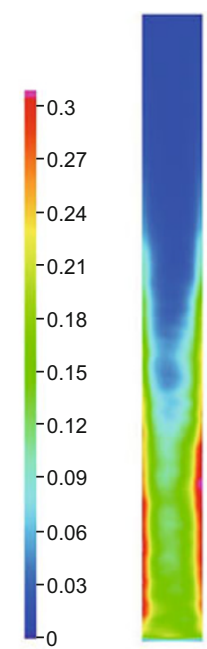

(c) FF regime
Fig. 4 Time-averaged solids volume fraction, (a) $U_{\mathrm{g}}=4.5 \mathrm{~m} \cdot \mathrm{s}^{-1}, G_{\mathrm{s}}=36.8$ $\mathrm{kg} \cdot \mathrm{m}^{-2} \cdot \mathrm{s}^{-1}$ (DPT regime); (b) $U_{\mathrm{g}}=3.9 \mathrm{~m} \cdot \mathrm{s}^{-1}, G_{\mathrm{s}}=33.7 \mathrm{~kg} \cdot \mathrm{m}^{-2} \cdot \mathrm{s}^{-1}$ (DPT regime); (c) $U_{\mathrm{g}}=3.2 \mathrm{~m} \cdot \mathrm{s}^{-1}, G_{\mathrm{s}}=26.6 \mathrm{~kg} \cdot \mathrm{m}^{-2} \cdot \mathrm{s}^{-1}$ (FF regime)

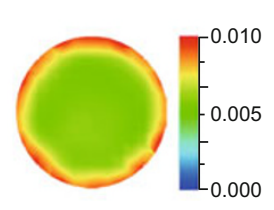

(a) DPT regime

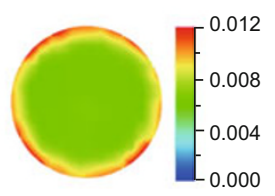

(b) DPT regime

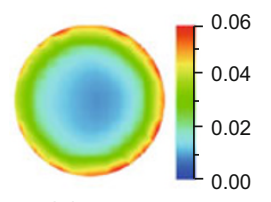

(c) FF regime
Fig. 5 Contours of time-averaged solids volume fraction at a horizontal section of $Z=5.46 \mathrm{~m}$, (a) $U_{\mathrm{g}}=4.5 \mathrm{~m} \cdot \mathrm{s}^{-1}, G_{\mathrm{s}}=36.8 \mathrm{~kg} \cdot \mathrm{m}^{-2} \cdot \mathrm{s}^{-1}$ (DPT regime); (b) $U_{\mathrm{g}}=3.9 \mathrm{~m} \cdot \mathrm{s}^{-1}, G_{\mathrm{s}}=33.7 \mathrm{~kg} \cdot \mathrm{m}^{-2} \cdot \mathrm{s}^{-1}$ (DPT regime); (c) $U_{\mathrm{g}}=3.2 \mathrm{~m} \cdot \mathrm{s}^{-1}, G_{\mathrm{s}}=26.6$ $\mathrm{kg} \cdot \mathrm{m}^{-2} \cdot \mathrm{s}^{-1}$ (FF regime)

volume fraction is distinctly higher and also its gradient is higher than in the DPT regime.

\subsection{Particle velocity}

The time-averaged particle velocity vectors at two vertical

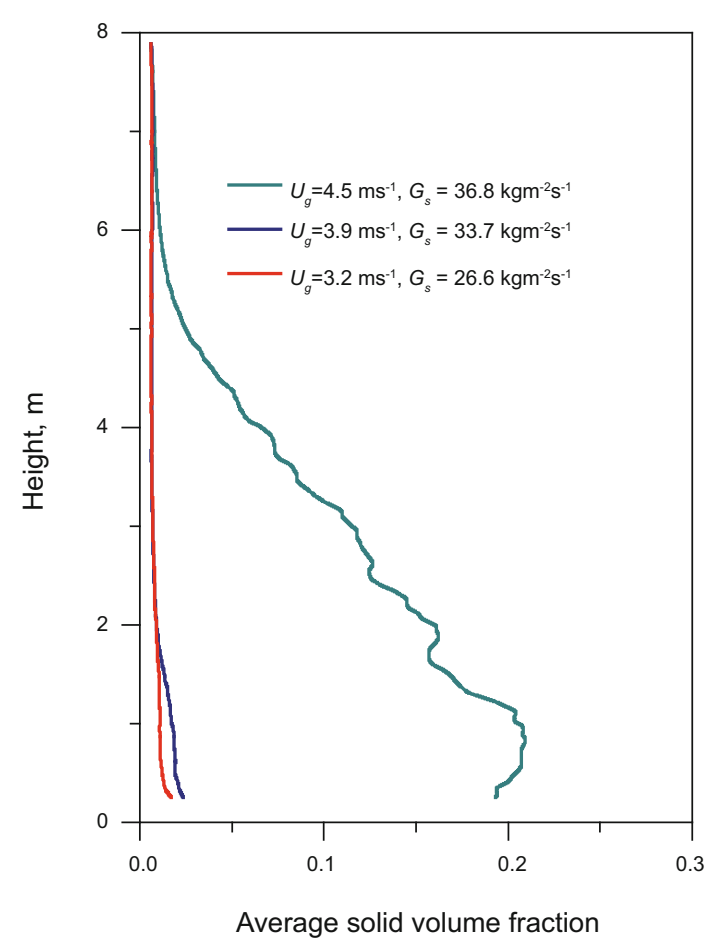

Fig. 6 Time-averaged axial solids volume fraction (a)

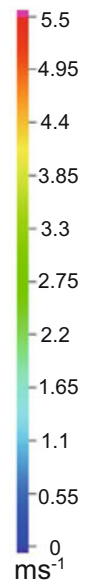

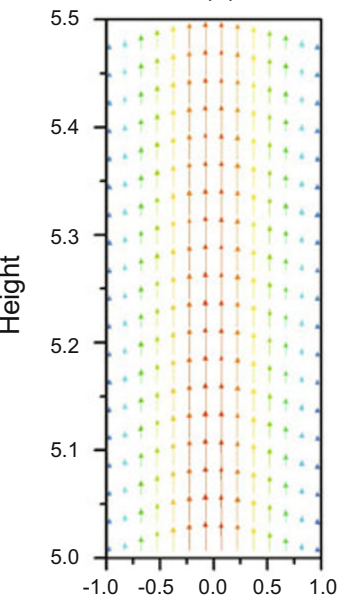

Radial position $(r / R)$ (b)

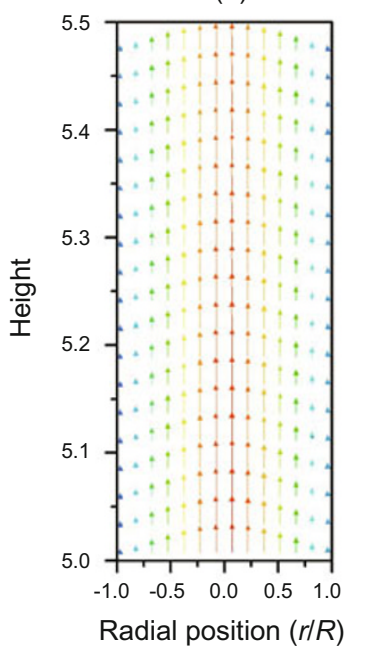

Fig. 7 Time-averaged particle velocity vectors in the DPT regime with $U_{\mathrm{g}}=4.5 \mathrm{~m} \cdot \mathrm{s}^{-1}$ and $G_{\mathrm{s}}=36.8 \mathrm{~kg} \cdot \mathrm{m}^{-2} \cdot \mathrm{s}^{-1}$, (a) cross-section $0-180^{\circ}$ (b) crosssection $90-270^{\circ}$

sections $\left(0-180^{\circ}\right.$ and $\left.90-270^{\circ}\right)$ are presented in Fig. 7 and Fig. 8. Fig. 7 shows the velocity vectors in the DPT regime at $U_{\mathrm{g}}=4.5 \mathrm{~m} \cdot \mathrm{s}^{-1}$ and $G_{\mathrm{s}}=36.8 \mathrm{~kg} \cdot \mathrm{m}^{-2} \cdot \mathrm{s}^{-1}$, and Fig. 8 shows the velocity vectors in the $\mathrm{FF}$ regime at $U_{\mathrm{g}}=3.2 \mathrm{~m} \cdot \mathrm{s}^{-1}$ and $G_{\mathrm{s}}=26.6 \mathrm{~kg} \cdot \mathrm{m}^{-2} \cdot \mathrm{s}^{-1}$. It can be seen from Fig. 7 and Fig. 8 that the solids flow pattern is also axis-symmetric in the timeaveraged sense. In the DPT regime, it can be seen in Fig. 7 that all the particles move upwards, regardless of position. While in the FF regime, except for the particles close to the wall, the solid particles also move upwards. The particles move upward in the center and downward close to the wall, 
(a)

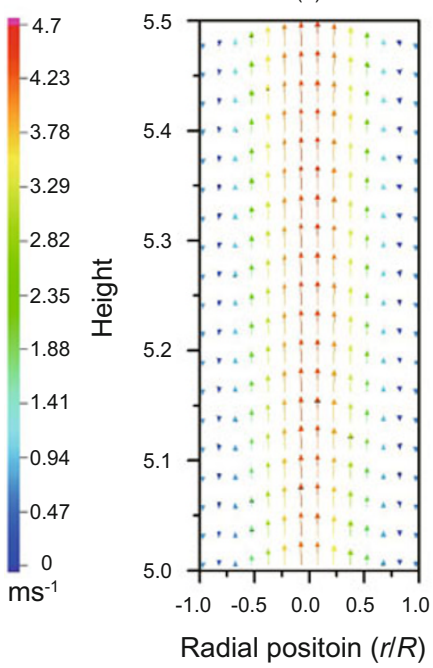

(b)

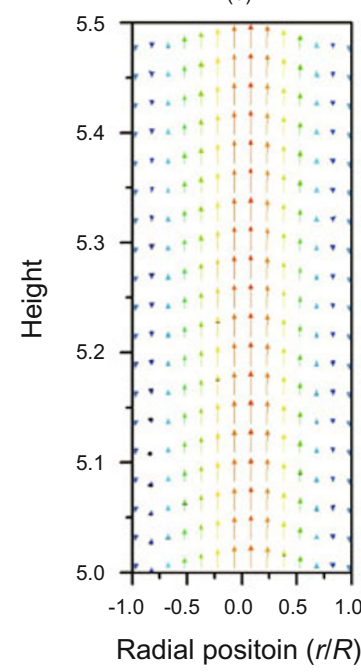

Fig. 8 Time-averaged particle velocity vectors in the FF regime with $U_{\mathrm{g}}=3.2 \mathrm{~m} \cdot \mathrm{s}^{-1}$ and $G_{\mathrm{s}}=26.6 \mathrm{~kg} \cdot \mathrm{m}^{-2} \cdot \mathrm{s}^{-1}$, (a) cross-section $0-180^{\circ}$ (b) crosssection $90-270^{\circ}$

leading to a core-annulus flow structure. This difference in the flow pattern between the DPT and FF regimes is attributed to the difference of their particle concentration. The increase of the solids holdup in FF regime can increase the formation of particle clusters, which tend to fall down, so in

FF regime particles close to the wall move downwards. Such flow pattern was also found by Bhusarapu et al (2006) at their measurement under the same conditions.

To quantitatively investigate the particle flow characteristics, the probability distribution functions (PDFs) of the particle velocities were introduced. Fig. 9 and Fig. 10 show the PDFs of the axial particle velocities at three radial positions $(r / R=0,0.461,0.922)$ and the bed height of $Z=5.46$ m.

Fig. 9 shows the PDFs of axial solids velocity in the DPT regime, with the superficial gas velocity of $4.5 \mathrm{~m} \cdot \mathrm{s}^{-1}$ and the solids mass flux of $36.8 \mathrm{~kg} \cdot \mathrm{m}^{-2} \cdot \mathrm{s}^{-1}$. It can be seen that the radial variation of the axial particle velocity is large, and the mean velocity decreases from the center to the wall. In the region close to the wall, the velocity of most of the particles is positive and only $14 \%$ of particles have a negative instantaneous velocity, resulting in a positive mean solids velocity. Therefore, in the DPT regime the phenomena of particle clustering and back mixing exist but not significantly. Similar conclusions are drawn from the PDFs of particles velocity under the other operating conditions in the DPT regime.

In the FF regime, Fig. 10 shows that the radial variation of the axial solids velocity is also significant and the mean velocity also decreases from the center to the wall. Compared to the DPT regime, the mean axial velocity in the center
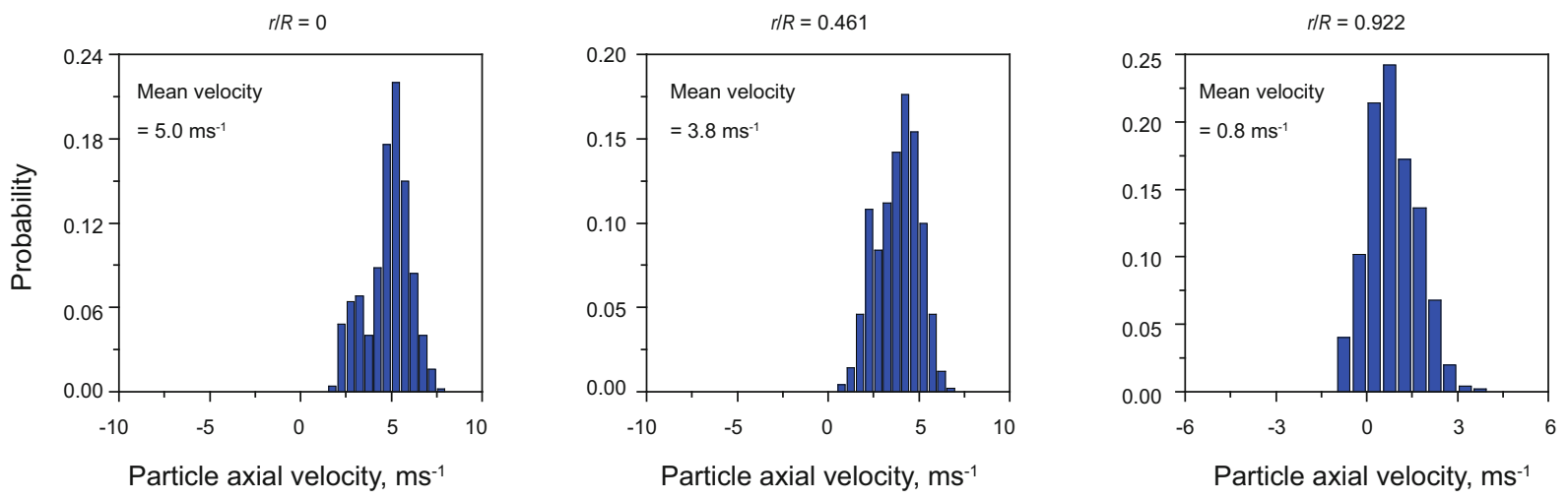

Fig. 9 The probability distribution functions (PDF) of particle axial velocity at three different radial locations and a bed height of $Z=5.46 \mathrm{~m}$ in the DPT regime at $U_{\mathrm{g}}=4.5 \mathrm{~m} \cdot \mathrm{s}^{-1}$ and $G_{\mathrm{s}}=36.8 \mathrm{~kg} \cdot \mathrm{m}^{-2} \cdot \mathrm{s}^{-1}$
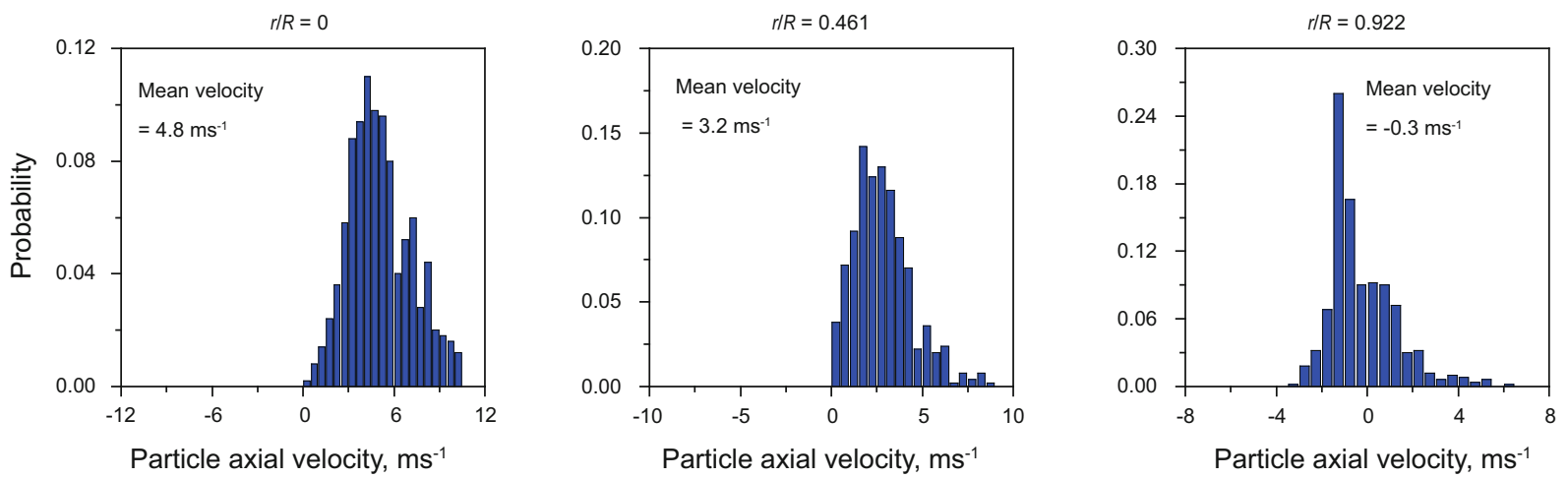

Fig. 10 The PDFs of particle axial velocity at three different radial locations and a bed height of $Z=5.46 \mathrm{~m}$ in the FF regime at $U_{\mathrm{g}}=3.2 \mathrm{~m} \cdot \mathrm{s}^{-1}$ and $G_{\mathrm{s}}=26.6 \mathrm{~kg} \cdot \mathrm{m}^{-2} \cdot \mathrm{s}^{-1}$ 
region is much higher than that close to the wall, and the mean axial velocity close to the wall is negative. Of the particles close to the wall, $64 \%$ have a negative velocity and the remained have positive velocity, and this leads to a negative mean velocity. The proportion of particles close to the wall moving downwards is much higher than in the DPT regime, indicating that in the FF regime the clustering effect increases, and the back mixing of the particles is more considerable.

\section{Conclusions}

The CPFD approach has been used to investigate the hydrodynamics of solids flow in a CFB riser under different operating conditions. The agreement between the simulated results with the experimental data from the literature showed that the CPFD model could predict the main features of the gas-solids flow in the DPT and FF regimes. The developed model is capable of describing the core-annular flow behavior and the phenomenon of solid phase clustering. The model also predicted the uniform dilute phase for the DPT regime, as well as the coexistence of the dilute phase in the upper region and the relative dense phase in the lower region for the FF regime. The average velocity of particles close to the wall was positive in the DPT regime, but negative in the FF regime. The formation of clusters and the back mixing of solids in the riser were stronger in the FF regime than in the DPT regime. However, there was a little disparity between the solids fraction and axial velocity with the experimental data in the FF regime. To obtain better predictions, the particle size distribution and turbulence model could be taken into consideration in the further investigation.

\section{Nomenclatures}

A Particle acceleration, $\mathrm{m} \cdot \mathrm{s}^{-2}$

$C_{\mathrm{d}} \quad$ Drag coefficient

$D \quad$ Drag force, $\mathrm{kg} \cdot \mathrm{m}^{-3} \cdot \mathrm{s}^{-1}$

$D_{1} \quad$ Drag force in the Wen and Yu model, $\mathrm{kg} \cdot \mathrm{m}^{-3} \cdot \mathrm{s}^{-1}$

$D_{2} \quad$ Drag force in the Ergun model, $\mathrm{kg} \cdot \mathrm{m}^{-3} \cdot \mathrm{s}^{-1}$

$d_{\mathrm{p}} \quad$ Particle diameter, $\mathrm{m}$

$f$ Particle probability distribution function

$F \quad$ Rate of momentum exchange per unit volume, $\mathrm{N} \cdot \mathrm{m}^{-3} \cdot \mathrm{s}^{-1}$

$g \quad$ Gravitational acceleration, $\mathrm{m} \cdot \mathrm{s}^{-2}$

$G_{\mathrm{s}} \quad$ Solids mass flux, $\mathrm{kg} \cdot \mathrm{m}^{-2} \cdot \mathrm{s}^{-1}$

$n_{\mathrm{p}} \quad$ Number of particles in a parcel

$N_{\mathrm{p}} \quad$ Total number of parcels or clouds

$P \quad$ Gas pressure, $\mathrm{Pa}$

$P_{\mathrm{s}} \quad$ Constant, $\mathrm{Pa}$

$r \quad$ Radial position, $\mathrm{m}$

$R \quad$ Radius of the riser, $\mathrm{m}$

Re Reynolds number

$S$ Interpolation operator

$t$ Time, $\mathrm{s}$

$u_{\mathrm{g}} \quad$ Gas velocity, $\mathrm{m} \cdot \mathrm{s}^{-1}$

$U_{\mathrm{g}} \quad$ Superficial gas velocity, $\mathrm{m} \cdot \mathrm{s}^{-1}$

$u_{\mathrm{p}} \quad$ Particle velocity, $\mathrm{m} \cdot \mathrm{s}^{-1}$

$V_{\mathrm{i}, \mathrm{j}, \mathrm{k}}$ Grid cell volume, $\mathrm{m}^{3}$
$V_{\mathrm{p}} \quad$ Particle volume, $\mathrm{m}^{3}$

$x_{\mathrm{p}} \quad$ Particle position, $\mathrm{m}$

$Z \quad$ Axial distance, $\mathrm{m}$

Greek Letters

$\mu_{\mathrm{g}} \quad$ Gas viscosity, $\mathrm{kg} \cdot \mathrm{m}^{-1} \cdot \mathrm{s}^{-1}$

$\rho_{\mathrm{g}} \quad$ Gas density, $\mathrm{kg} \cdot \mathrm{m}^{-3}$

$\rho_{\mathrm{p}} \quad$ Particle density, $\mathrm{kg} \cdot \mathrm{m}^{-3}$

$\tau_{\mathrm{p}} \quad$ Particle normal stress, $\mathrm{N} \cdot \mathrm{m}^{-2}$

$\theta_{\mathrm{g}} \quad$ Gas volume fraction

$\theta_{\mathrm{p}} \quad$ Particle volume fraction

$\theta_{\mathrm{CP}}$ particle-phase volume fraction at close packing

\section{Acknowledgements}

The authors acknowledge the support by the National Basic Research Program (Grant No. 2010CB226906, and 2012CB215000). The authors also thank the anonymous referees for their comments on this manuscript.

\section{References}

Abbasi A, Ege P E and Lasa H I. CPFD simulation of a fast fluidized bed steam coal gasifier feeding section. Chemical Engineering Journal. 2011. 174(1): 341-350

Almuttahar A and Taghipour F. Computational fluid dynamics of a circulating fluidized bed under various fluidization conditions. Chemical Engineering Science. 2008. 63(6): 1696-1709

Almuttahar A and Taghipour F. Computational fluid dynamics of high density circulating fluidized bed riser: Study of modeling parameters. Powder Technology. 2008. 185(1): 11-23

Benyahia S, Arastoopour H, Knowltonet T M, et al. Simulation of particles and gas flow behavior in the riser section of a circulating fluidized bed using the kinetic theory approach for the particulate phase. Powder Technology. 2000. 112(1-2): 24-33

Bhusarapu S, Al-Dahhan M H and Dudukovic M P. Quantification of solids flow in a gas-solid riser: single radioactive particle tracking. Chemical Engineering Science. 2004. 59(22-23): 5381-5386

Bhusarapu S, Al-Dahhan M H and Dudukovic M P. Solids flow mapping in a gas-solid riser: Mean holdup and velocity fields. Powder Technology. 2006. 163(1-2): 98-123

Bhusarapu S, Al-Dahhan M H, Dudukovic M P, et al. Experimental study of the solids velocity field in gas-solid risers. Industrial \& Engineering Chemistry Research. 2005. 44(25): 9739-9749

Bhusarapu S, Cassanello M, Al-Dahhan M H, et al. Dynamical features of the solid motion in gas-solid risers. International Journal of Multiphase Flow. 2007. 33(2): 164-181

Chan C K, Guo Y C and Lau K S. Numerical modeling of gasparticle flow using a comprehensive kinetic theory with turbulence modulation. Powder Technology. 2005. 150(1): 42-55

Chew J W, Wolz J R and Hrenya C M. Axial segregation in bubbling gas-fluidized beds with Gaussian and lognormal distributions of Geldart Group B particles. AIChE Journal. 2010. 56(12): 3049-3061

Chiesa M, Mathiesen V, Melheim J A, et al. Numerical simulation of particulate flow by the Eulerian-Lagrangian and the EulerianEulerian approach with application to a fluidized bed. Computers \& Chemical Engineering. 2005. 29(2): 291-304

Ergun S. Fluid flow through packed columns. Chemical Engineering Progress. 1952. 48: 89-94

Gidaspow D. Multiphase Flow and Fluidization: Continuum and Kinetic Theory Descriptions. Boston: Academic Press. 1994

Godlieb W, Deen N G and Kuipers J A M. A discrete particle simulation study of solids mixing in a pressurized fluidized bed. The ECI Conference on the12th International Conference on Fluidization 
- New Horizons in Fluidization Engineering. 2007, Vancouver, Canada

Grace J R, Bi H T and Golriz M. Handbook of Fluidization and FluidParticle Systems: Circulating Fluidized Beds. New York: Marcel Dekker. 2003

Grace J R and Sun G. Influence of particle size distribution on the performance of fluidized bed reactors. The Canadian Journal of Chemical Engineering. 1991. 69(5): 1126-1134

Harris S E and Crighton D G. Solitons, solitary waves, and voidage disturbances in gas-fluidized beds. Journal of Fluid Mechanics. 1994. 266: 243-276

Jin B S, Wang X F, Zhong W Q, et al. Modeling on high-flux circulating fluidized bed with Geldart Group B particles by kinetic theory of granular flow. Energy \& Fuels. 2010. 24(5): 3159-3172

Kafui D K, Johnson S, Thornton C, et al. Parallelization of a LagrangianEulerian DEM/CFD code for application to fluidized beds. Powder Technology. 2011. 207(1-3): 270-278

Lu H L, Wang S Y, Ding J M, et al. Numerical simulation of flow behavior of particles and clusters in riser using two granular temperatures. Powder Technology. 2008. 182(2): 282-293

Neri A and Gidaspow D. Riser hydrodynamics: Simulation using kinetic theory. AIChE Journal. 2000. 46(1): 52-67

O'Rourke P J, Zhao P and Snider D M. A model for collisional exchange in gas/liquid/solid fluidized beds. Chemical Engineering Science. 2009. 64(8): 1784-1797

Sakai M, Yamada Y, Shigeto Y, et al. Large-scale discrete element modeling in a fluidized bed. International Journal for Numerical Methods in Fluids. 2010. 64(10-12): 1319-1335

Snider D M. An incompressible three-dimensional multiphase particlein-cell model for dense particle flows. Journal of Computational Physics. 2001. 170(2): 523-549

Snider D M. Three fundamental granular flow experiments and CPFD predictions. Powder Technology. 2007. 176(1): 36-46

Snider D M, Clark S M and O'Rourke P J. Eulerian-Lagrangian method for three-dimensional thermal reacting flow with application to coal gasifiers. Chemical Engineering Science. 2011. 66(6): 1285-1295

Wen C Y and Yu Y H. Mechanics of fluidization. Chemical Engineering Progress Symposium Series. 1966. 62(2): 100-111

Wu C N, Cheng Y, Ding Y L, et al. CFD-DEM simulation of gas-solid reacting flows in fluid catalytic cracking (FCC) process. Chemical Engineering Science. 2010. 65(1): 542-549

Zheng Y, Wan X T, Qian Z, et al. Numerical simulation of the gasparticle turbulent flow in riser reactor based on $\mathrm{k}-\varepsilon-\mathrm{k}_{\mathrm{p}}-\varepsilon_{\mathrm{p}}-\Theta$ twofluid model. Chemical Engineering Science. 2001. 56(24): 68136822

Zhu H P, Zhou Z Y, Yang R Y, et al. Discrete particle simulation of particulate systems: A review of major applications and findings. Chemical Engineering Science. 2008. 63(23): 5728-5770

Zhu J X and Bi H T. Distinctions between low density and high density circulating fluidized beds. The Canadian Journal of Chemical Engineering. 1995. 73(5): 644-649

(Edited by Zhu Xiuqin) 